Cite this: J. Mater. Chem. A, 2013, 1 12797

Received 30th June 2013

Accepted 22nd August 2013

DOI: $10.1039 / c 3 t a 12548 c$

www.rsc.org/MaterialsA

\section{Synthesis, characterization and application of lanthanum-impregnated activated alumina for $F$ removal $\uparrow$}

\begin{abstract}
Qiantao Shi, ${ }^{a}$ Yuying Huang ${ }^{b}$ and Chuanyong Jing ${ }^{* a}$
Elevated fluoride (F) in groundwater presents an obvious environmental concern. Adsorption using activated alumina (AA) is currently the best available technology for $F$ removal, despite its low efficiency, $\mathrm{pH}$ dependence, and aluminium (Al) release. The motivation for our study is to synthesise a new $\mathrm{F}$ adsorbent by impregnating commercially available granulated AA with lanthanum oxide (LAA), and to explore its $\mathrm{F}$ adsorption mechanism on the molecular scale. Five cycles of lanthanum impregnation on AA followed by calcination at $573 \mathrm{~K}$ increased the La content up to $19.1 \%$ and the $\mathrm{F}$ removal from $18.1 \%$ by pristine AA to $92.4 \%$ by LAA. The SEM, TEM, XRD, TGA, and EXAFS results demonstrated that the 5-20 nm thin flakes of $\mathrm{LaOOH}$ on LAA were in an amorphous form, with 7.6 oxygen atoms around each La. This $\mathrm{LaOOH}$ layer was uniformly distributed inside the micropores of the 1-3 mm AA granules. LAA exhibited four fold higher $\mathrm{F}$ adsorption capacity than $\mathrm{AA}$ in the $\mathrm{pH}$ range 3.9 to 9.6 , with substantially reduced Al release. The ability to regenerate and reuse LAA makes it an attractive sustainable material. Multiple complementary spectroscopic analyses demonstrated that ligand exchange between $\mathrm{F}$ and surface hydroxyl groups is the mechanism for $\mathrm{F}$ adsorption on LAA. Our work improves the understanding of $\mathrm{F}$ interaction with metal oxides on the molecular scale and presents an alternative solution for elevated $\mathrm{F}$ water treatment.
\end{abstract}

\section{Introduction}

Naturally occurring fluoride (F) in groundwater is causing increasing public concern due to its health effects. About 200 million people drink water with $\mathrm{F}$ concentrations exceeding the World Health Organization (WHO) guideline of $1.5 \mathrm{mg} \mathrm{L}^{-1}{ }^{1}$ Long-term exposure to F-rich water leads to dental and skeletal fluorosis. ${ }^{2}$

The $\mathrm{F}$ removal from groundwater is still a challenge in rural areas of developing countries such as China and India ${ }^{3,4}$ due to the lack of efficient adsorptive materials. Currently, activated alumina (AA) is a widely used adsorbent, and AA-based

\footnotetext{
${ }^{a}$ State Key Laboratory of Environmental Chemistry and Eco-toxicology, Research Center for Eco-Environmental Science, Chinese Academy of Science, Beijing 100085, China. E-mail: cyjing@rcees.ac.cn; Fax: +86010 62849523; Tel: +86 01062849523 ${ }^{b}$ Shanghai Synchrotron Radiation Facility, Shanghai Institute of Applied Physics, Chinese Academy of Sciences, Shanghai 201214, China

$\dagger$ Electronic supplementary information (ESI) available: Fig. S1: photo of LAA; Fig. S2: XRD patterns of various LAAs synthesized at different calcination temperatures; Table S1: pore volume and diameter of AA and LAA; Fig. S3: EDS of flake structures on LAA; Fig. S4: EDS elemental mapping of F, La, and $\mathrm{Al}$ on LAA with adsorbed F; Fig. S5: high resolution transmission electron microscope HRTEM of LAA; Table S2: structure parameters derived from $\mathrm{La} \mathrm{L}_{\mathrm{III}}$-edge EXAFS analysis; Fig. S6: high resolution XPS surveys of F 1s for spent AA (A), LAA (B), and $\mathrm{LaOOH}(\mathrm{C})$; Fig. S7: isotherm of LaOOH and the mixture of AA and $\mathrm{LaOOH}$. Fig. S8: mechanical strength of AA and LAA; Fig. S9: La release from LAA as a function of solution $\mathrm{pH}$. See DOI: $10.1039 / \mathrm{c} 3 \mathrm{ta} 12548 \mathrm{c}$
}

adsorption is the best available technology for defluoridation. ${ }^{1,5}$ However, AA is also recognized to have well-known limitations, including reduced $\mathrm{F}$ adsorption capacity at $\mathrm{pH}>6^{6}$ and the release of aluminium (Al), which may lead to secondary Al contamination. ${ }^{7}$ Therefore, the need to improve the existing AA for enhanced $\mathrm{F}$ removal with wide $\mathrm{pH}$ range applicability and minimal Al leaching ability motivates our study.

Recently, extensive studies have been performed by impregnating AA with alum, ${ }^{8}$ manganese, ${ }^{9-11}$ magnesium, ${ }^{12}$ iron, ${ }^{13,14}$ lithium ${ }^{15}$ and lanthanum ${ }^{16}$ to improve $\mathrm{F}$ adsorption. Among these methods, lanthanum (La) impregnation has been proved to be most promising because of its specific affinity for $\mathrm{F}{ }^{16,17}$ Wasay et al. were the first to add La on AA by mixing 0.1 mm diameter AA particles with La solution at $\mathrm{pH} 7.5$ for $48 \mathrm{~h}$. The resulting material increased the $\mathrm{F}$ adsorption capacity from $3.31 \mathrm{mg} \mathrm{g}^{-1}$ to $6.23 \mathrm{mg} \mathrm{g}^{-1} \cdot{ }^{16}$ Meanwhile, enhanced $\mathrm{F}$ removal was also reported for La impregnation on various supports such as gelatine, ${ }^{18}$ amberlite resins, ${ }^{19}$ and chitosan. $^{20,21}$

However, the synthesis procedure for La-doped AA (LAA) was not fully optimized. The La impregnation on AA achieved previously was $3.3 \%,{ }^{16,22}$ which could potentially be increased to improve $\mathrm{F}$ adsorption. The fabrication of AA with uniformly distributed La is needed. In addition, the F adsorption mechanism on LAA is not well understood on the molecular level. 
The lack of this crucial knowledge constrains our ability to design, synthesize, and regenerate an effective $\mathrm{F}$ adsorbent.

The objectives of this study were (1) to synthesize highly efficient LAA for elevated $\mathrm{F}$ removal, and (2) to explore the adsorption mechanism on the molecular level. La was uniformly loaded on AA repeatedly using ultrasonic irradiation and calcination. Batch adsorption experiments and multiple complementary characterization techniques including BET, TGA, FESEM/EDS, HRTEM, XRD, EXAFS, Raman, and XPS were used to study the interactions of $\mathrm{F}$ and LAA. The insights gained from this study should shed light on $\mathrm{F}$ adsorption using the composite material LAA.

\section{Experimental section}

\section{Materials}

Commercial granular AA optimized for $\mathrm{F}$ removal with a diameter of 1-3 mm (Keyuan, China, Fig. S1†) was used without further purification. NaF was heated at $393 \mathrm{~K}$ for $2 \mathrm{~h}$ before use.

A stock solution of $1000 \mathrm{mg} \mathrm{L}^{-1} \mathrm{~F}$ was prepared by dissolving $2.210 \mathrm{~g} \mathrm{NaF}$ in $1 \mathrm{~L}$ deionized (DI) water (18.2 M $\Omega$, Milli-Q), and stored in a refrigerator at $277 \mathrm{~K}$. The La solution was prepared by dissolving $19.485 \mathrm{~g}$ analytical grade $\mathrm{La}\left(\mathrm{NO}_{3}\right)_{3} \cdot 6 \mathrm{H}_{2} \mathrm{O}$ in $50 \mathrm{~mL}$ DI water, and the $\mathrm{pH}$ was adjusted to $6.0 \mathrm{using} \mathrm{NH}_{3} \cdot \mathrm{H}_{2} \mathrm{O}$. A background electrolyte of $0.01 \mathrm{~mol} \mathrm{~L}^{-1} \mathrm{NaClO}_{4}$ was used in the experiment. $0.1 \mathrm{~mol} \mathrm{~L}^{-1} \mathrm{HClO}_{4}$ and $\mathrm{NaOH}$ were used to adjust the solution $\mathrm{pH}$. All regents were obtained from Sinopharm. China.

\section{Preparation of LAA and LaOOH}

LAA was prepared by impregnating AA with La oxides. Briefly, AA was washed with DI water, and then dried at $328 \mathrm{~K}$. To impregnate La on AA, a mixture of $10 \mathrm{~mL}$ La solution and $14.5 \mathrm{~g}$ AA was sonicated for $4 \mathrm{~h}$, then the solid was separated and dried at $328 \mathrm{~K}$. The solid was then calcined for $4 \mathrm{~h}$ at various temperatures. After the obtained material was cooled down, it was washed with DI water until the conductivity was below 100 $\mu \mathrm{S} \mathrm{cm}^{-1}$. The impregnation process was repeated and the amount of La loaded on AA was calculated based on mass balance. Lanthanum oxyhydroxide (LaOOH) was also synthesized using the same process in the absence of AA.

\section{Characterization}

The Brunauer-Emmett-Teller (BET) surface area of the granules was determined using an automated surface area analyzer (AutosorbiQ, US).

To investigate the surface morphology, spent granular adsorbents were cut into hemispheres. Then, the cross-section of the hemisphere was examined using field emission scanning electron microscopy (FESEM) with an Oxford energy dispersive X-rayspectroscopy (EDS) analyzer (SU 8020, Hitachi, Japan).

The solid sample was ground and passed through a 200mesh sieve for characterization. The crystal morphology was characterized using high resolution transmission electron microscopy (HRTEM, JEM2010, JEOL, Japan). X-ray powder diffraction (XRD, X'Pert PRO MPD, PANalytical, The Netherlands) data were recorded on a Rigaku D/Max-2500 diffractometer at $40 \mathrm{kV}, 100 \mathrm{~mA}$ using a Cu-target tube $(\lambda=1.5418)$ and a graphite monochromator. Scans were made in the $2 \theta$ range of $5^{\circ}$ to $90^{\circ}$ with a step size of $0.01^{\circ}$ and a count time of $2 \mathrm{~s}$ per step. Analysis of the XRD patterns was performed using the PDF-2 reference database from the International Center for Diffraction Data (ICDD) database. X-ray photoelectron spectroscopy (XPS, ESCALAB 250, Thermo Fisher Sci., US) was used to investigate the chemical properties of adsorbents before and after $\mathrm{F}$ adsorption. The binding energies obtained in the XPS analysis were calibrated against the $C$ 1s peak at $284.8 \mathrm{eV}$. The XPS data processing and peak fitting were performed using the XPSPeak software package. Raman spectra were obtained using a portable Raman spectrometer (Enwave Optronics, Inc. USA) with a $4 \mathrm{~cm}^{-1}$ resolution at $785 \mathrm{~nm}$ excitation energy.

The samples for extended X-ray absorption fine structure (EXAFS) spectroscopy were sealed between two layers of Kapton tape, and La $\mathrm{L}_{\mathrm{III}}$-edge data were collected on beamline $14 \mathrm{~W} 1$ at the Shanghai Synchrotron Radiation Facility (SSRF), China. The detailed information on sample collection and data processing are shown in the ESI. $\dagger$

In the thermogravimetric analysis (TGA), AA powder was evaluated on a TA SDTQ600 (TA instruments, US) in the temperature range of $298 \mathrm{~K}$ to $1283 \mathrm{~K}$ with a nitrogen flow rate of $100 \mathrm{~mL} \mathrm{~min}^{-1}$ and a heating rate of $10 \mathrm{~K} \mathrm{~min}^{-1}$. The LAA and $\mathrm{LaOOH}$ powder samples subjected to TGA analysis were synthesized without the calcination step.

\section{Adsorption experiments}

Batch adsorption experiments were conducted to compare the effectiveness of the adsorbents. In a typical experiment, $0.1 \mathrm{~g}$ adsorbent was mixed with $100 \mathrm{~mL} \mathrm{~F}$ solution at the desired $\mathrm{pH}$ value. The samples were mixed on a rotary shaker at $200 \mathrm{rpm}$ at $298 \mathrm{~K}$ for $24 \mathrm{~h}$. The solution $\mathrm{pH}$ was adjusted with $\mathrm{HClO}_{4}$ and $\mathrm{NaOH}$.

The $\mathrm{pH}$ edge adsorption experiments of $10 \mathrm{mg} \mathrm{L}^{-1} \mathrm{~F}$ on $1 \mathrm{~g}$ $\mathrm{L}^{-1}$ AA were conducted as a function of solution $\mathrm{pH}$. Suspension samples in $0.01 \mathrm{~mol} \mathrm{~L}^{-1} \mathrm{NaClO}_{4}$ were adjusted to desired $\mathrm{pH}$ values with $\mathrm{NaOH}$ and $\mathrm{HClO}_{4}$. The adsorption isotherms of AA and LAA were investigated at pH 7 in $0.01 \mathrm{~mol} \mathrm{~L}^{-1} \mathrm{NaClO}_{4}$ solution. The adsorbent concentration was fixed at $1 \mathrm{~g} \mathrm{~L}^{-1}$, and the $\mathrm{F}$ concentration was increased up to $100 \mathrm{mg} \mathrm{L}^{-1}$. After being mixed on a rotary shaker at $200 \mathrm{rpm}$ for $24 \mathrm{~h}$ at $298 \mathrm{~K}$, samples were centrifuged and passed through a $0.45 \mu \mathrm{m}$ membrane filter for analysis.

To explore the regeneration and reuse, LAA was mixed with $100 \mathrm{mg} \mathrm{L}^{-1} \mathrm{~F}$ and $0.01 \mathrm{~mol} \mathrm{~L}^{-1} \mathrm{NaClO}_{4}$. Then, the spent LAA was regenerated using $1 \mathrm{~mol} \mathrm{~L}^{-1} \mathrm{NaOH}$ for $3 \mathrm{~h}$ before the next adsorption or re-use cycle.

The $\mathrm{F}$ concentration was measured using an $\mathrm{F}$ ion-selective electrode (Orion, Thermo Fisher Sci., US). Concentrations of Al and La were determined using an inductively coupled plasmamass spectrometer (ICP-MS, Agilent 7500a, US). 


\section{Results and discussion}

The calcination temperature for LAA synthesis played a critical role in its subsequent $\mathrm{F}$ removal (Fig. 1). $\mathrm{F}$ removal increased from $31.2 \%$ for calcination at $373 \mathrm{~K}$ to a maximum of $42 \%$ at $573 \mathrm{~K}$, and then decreased to $13.25 \%$ at $1273 \mathrm{~K}$. However, the percentage of La loaded on AA increased from $2.4 \%$ for calcination at $373 \mathrm{~K}$ to $8.6 \%$ at $673 \mathrm{~K}$ and remained constant thereafter. Because the maximum $\mathrm{F}$ removal was found for LAA synthesized at $573 \mathrm{~K}$ and the maximum La loading at $673 \mathrm{~K}$, we therefore investigated the effect of multiple La impregnations at $573 \mathrm{~K}$ and $673 \mathrm{~K}$.

F removal increased from $18.1 \%$ using pristine AA to $92.4 \%$ upon five cycles of La impregnation with calcination at $573 \mathrm{~K}$ (Fig. 2). Meanwhile, F removal reached the maximum of $51.3 \%$ after three cycles of impregnation with calcination at $673 \mathrm{~K}$, and decreased substantially with further increasing impregnationcalcination cycles. The results showed that the maximum $\mathrm{F}$ removal can be achieved by stepwise La impregnation and $573 \mathrm{~K}$ calcination for five cycles.

The calcination temperature usually determines the crystal structure of La oxides, ${ }^{23,24}$ which is critical in F adsorption. To investigate the structure of the La-oxide coatings, XRD analysis was used for LAA calcined at various temperatures, but no crystalline La oxide was found (Fig. S2 $\uparrow$ ). Therefore, the change in $\mathrm{F}$ adsorption (Fig. 2) was not due a change in the crystal structure of La oxides, prompting further investigation using TGA and BET.

Our TGA results in Fig. 3 show the transformation of $\mathrm{LaOOH}$ to $\mathrm{La}_{2} \mathrm{O}_{3}$ over $573 \mathrm{~K}$. The weight losses from 495 to 565 $\mathrm{K}$ of AA (1.18\%, Fig. 3a) and from 498 to $564 \mathrm{~K}$ of LAA $(2.59 \%$, Fig. $3 \mathrm{~b})$ were attributed to the adsorbed water. The weight loss from 502 to $646 \mathrm{~K}$ of $\mathrm{LaOOH}(8.15 \%$, Fig. 3c) was due to the adsorbed water and formation of $\mathrm{LaOOH}^{25}$ Moreover, the change of $\mathrm{LaOOH}$ to $\mathrm{La}_{2} \mathrm{O}_{3}$ induced the weight loss from 561 to $858 \mathrm{~K}$ of LAA (9.92\%, Fig. 3b) and from 646 to $892 \mathrm{~K}(16.28 \%$, Fig. 3c) of $\mathrm{LaOOH} .^{25,26}$ The $\mathrm{F}$ affinity of crystalline $\mathrm{La}_{2} \mathrm{O}_{3}$ was lower than that of amorphous $\mathrm{LaOOH}^{27}$ as evidenced by the

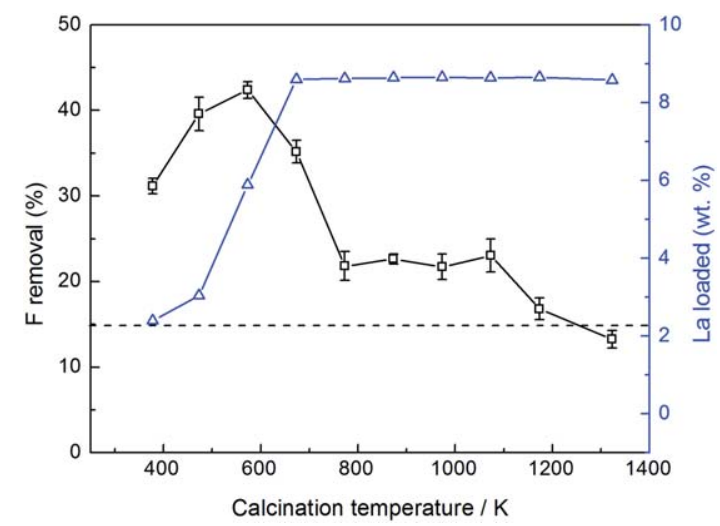

Fig. 1 Evaluation of LAA synthesized at different calcination temperatures for $F$ removal $(\square)$ and La content $(\Delta)$. The dashed line represents $F$ removal using AA. Adsorbent $=1 \mathrm{~g} \mathrm{~L}^{-1}$, initial $\mathrm{F}$ concentration $=10 \mathrm{mg} \mathrm{L}^{-1}, \mathrm{pH}=7$, temperature $=$ $298 \pm 2 \mathrm{~K}$.
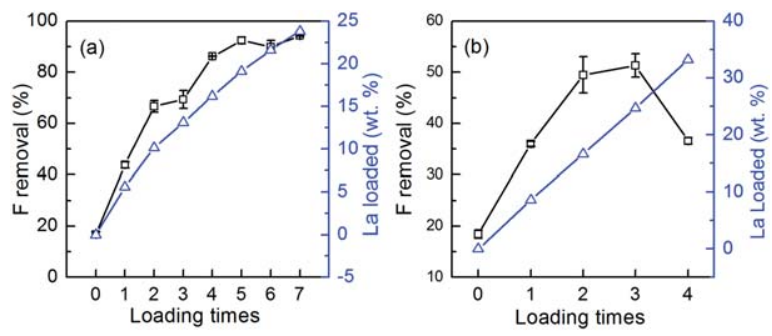

Fig. 2 Comparison of LAA synthesized with calcination at $573 \mathrm{~K}(\mathrm{a})$ and $673 \mathrm{~K}$ (b) for $\mathrm{F}$ removal $(\square)$ and La content $(\Delta)$. Adsorbent $=1 \mathrm{~g} \mathrm{~L}^{-1}$, initial F concentration $=10 \mathrm{mg} \mathrm{L}^{-1}, \mathrm{pH}=7$, temperature $=298 \pm 2 \mathrm{~K}$.

significant decrease in $\mathrm{F}$ adsorption after calcination over 573 K (Fig. 1). In agreement with our observation, Rosynek and Yang also found that $\mathrm{LaOOH}$ was transformed to $\mathrm{La}_{2} \mathrm{O}_{3}$ from 564 to $858 \mathrm{~K}^{25,28}$

The BET results showed that the surface area decreased from $235 \mathrm{~m}^{2} \mathrm{~g}^{-1}$ to 192 and $140 \mathrm{~m}^{2} \mathrm{~g}^{-1}$ upon five and seven cycles of La loading, respectively (Fig. 4). The observation confirmed that the optimum number of La loading cycles was five. When the number of impregnation-calcination cycles was less than five, the decrease in BET area was balanced by the increase in active LaOOH sites. Additional impregnation beyond five times could not improve the amount of effective $\mathrm{LaOOH}$, resulting in relatively constant $\mathrm{F}$ adsorption (Fig. 2). The phenomenon of decreased surface area after impregnation was in accordance with previous observations. ${ }^{\mathbf{1 0 , 1 2 , 2 9 , 3 0}}$

To investigate the surface morphology, FESEM analyses were performed on the hemispherical cross-sections of AA and LAA synthesized with different numbers of loading cycles (Fig. 5). Compared with AA (Fig. 5a), thin flakes $(5-20 \mathrm{~nm}$ thickness) appeared on the surface of LAA (Fig. 5b, c and d). Moreover, with the increase in La loading, the amount of thin flakes increased. The primary element of the flake was La (wt. $86.53 \%$, Fig. S3†), while no flakes were observed on AA (Fig. 5a). In addition, the results of elemental mapping for the F-adsorbed LAA (LAA-F) sample showed that LaOOH and fluoride were uniformly distributed on the cross-section (Fig. S4†).

Though thin flakes were formed, no new crystalline phase other than that from $\mathrm{Al}_{2} \mathrm{O}_{3}$ was detected using XRD (Fig. $\mathrm{S} 2 \dagger$ ). The XRD results implied that LaOOH on LAA was in an amorphous phase. To confirm the XRD conclusion, we further measured the interplanar distance using HRTEM (Fig. S5 $\dagger$ ). The observed distance was $1.98 \AA$, corresponding to the (104) diffraction line of $\chi-\mathrm{Al}_{2} \mathrm{O}_{3}$ (PDF no. 13-0373). Both XRD and HRTEM results showed that the impregnated $\mathrm{LaOOH}$ was in an amorphous form.

To obtain the LAA structure on the molecular level, EXAFS was used to determine the La local coordination environment in LaOOH and LAA (Fig. 6). The $k^{2}$-weighted La $\mathrm{L}_{\mathrm{III}}$-edge EXAFS spectra and the corresponding radial structure functions (RSF) as magnitude and real part of the Fourier transformation (FT) vs. radial distance are shown in Fig. 6 . The structure parameters listed in Table $\mathrm{S} 2 \uparrow$ were obtained by fitting the theoretical curves to the experimental spectra. 

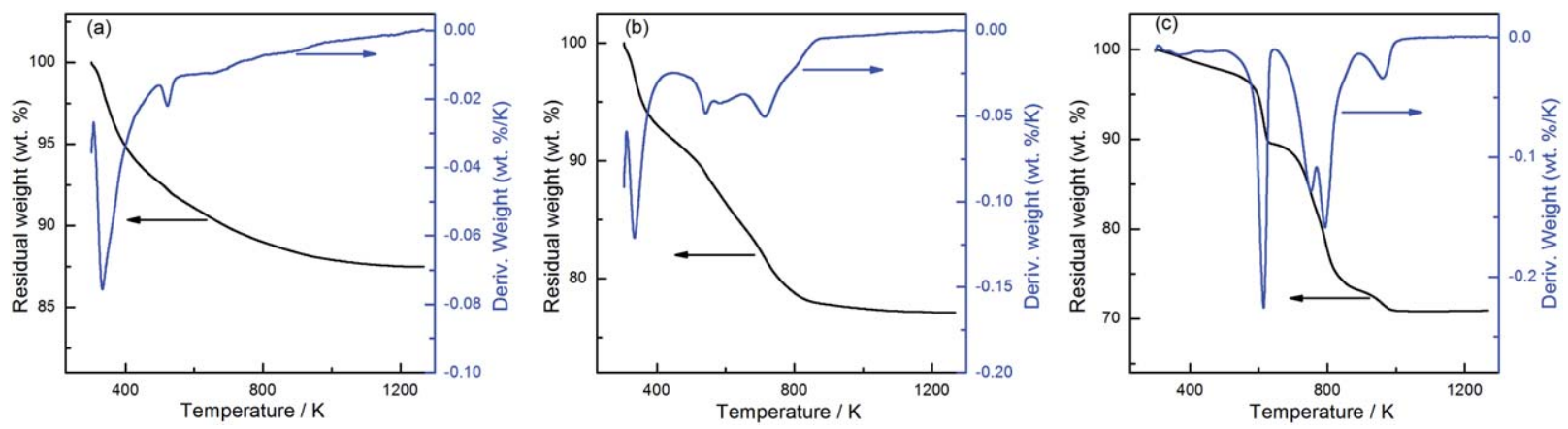

Fig. 3 TGA of AA (a), LAA (b), and $\mathrm{LaOOH}(c)$.

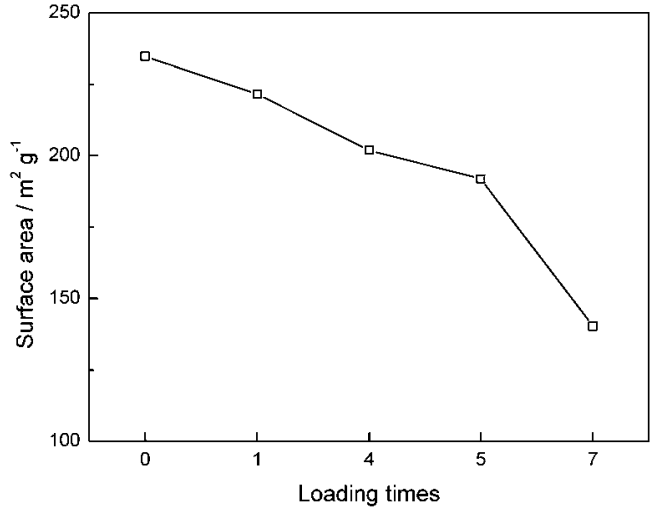

Fig. 4 Surface area of LAA at different La loading times.
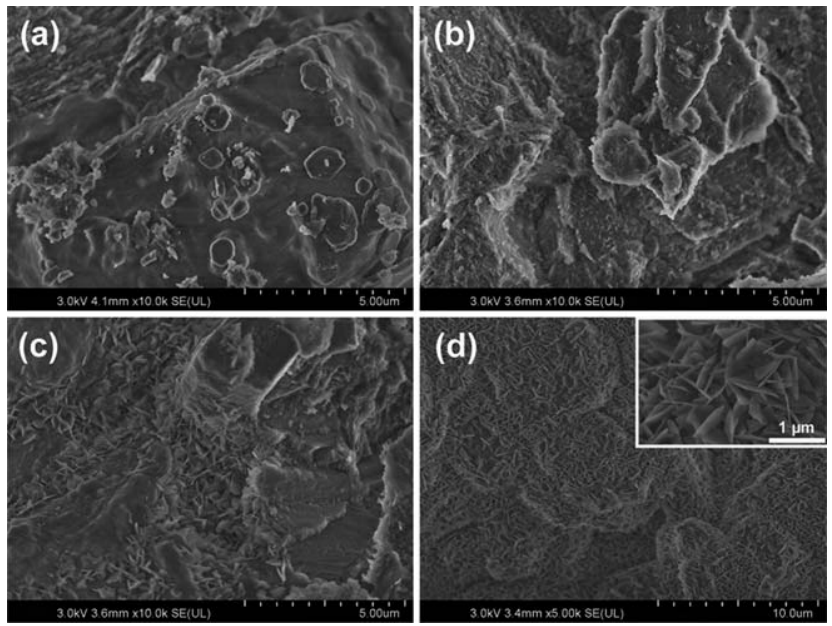

Fig. 5 FESEM images of AA (a), one cycle La loading (b), two cycles La loading (c), and five cycles La loading (d). (Inset in d: high-magnification FESEM image).

Based on the fit of the theoretical to the experimental spectra, the first and strongest peak in the FT curve indicated there was 7.6 oxygen atoms at an average distance of $2.58 \AA$ for the LaOOH sample. An additional oxygen atom was found at $3.56 \AA$. The third peak in the FT spectra was due to $3.3 \mathrm{La}$ at $4.22 \AA$. The distances and coordination numbers $(\mathrm{CNs})$ of $\mathrm{La}-\mathrm{O}$ and La-La were in good agreement with previously published
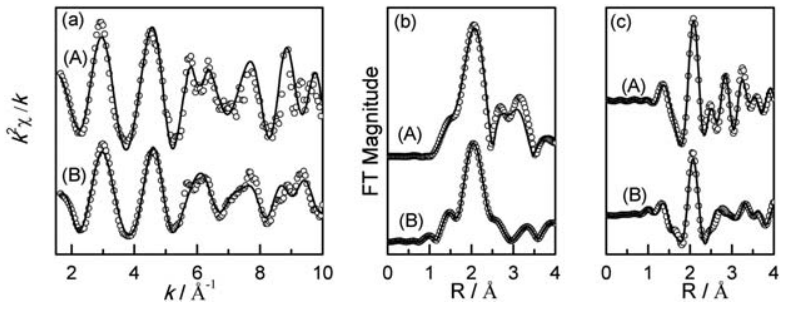

Fig. 6 Normalized $k^{2}$-weighted observed (dotted line) and model calculated (solid line) La LIII-edge EXAFS spectra (a), the corresponding Fourier transformed magnitude (b) and real parts of Fourier transform (c) for LAA (A) and $\mathrm{LaOOH}(\mathrm{B})$ samples.

data. $^{31,32}$ When La was coated on AA, the first La-O shell remained unchanged. $\mathrm{Al}$ atoms were detected at $3.19 \AA$ with a $\mathrm{CN}$ of 3.7. This structure change from $\mathrm{LaOOH}$ demonstrated that La was adsorbed on the surface of AA. The La $\mathrm{L}_{\mathrm{II}}$-edge at 410 $\mathrm{eV}$ beyond the $\mathrm{L}_{\mathrm{III}}$-edge complicated the data analysis because truncation led to a limited data range in $k$-space. Therefore, the FT peaks higher than $4.5 \AA$ a were unresolved.

XPS surveys of $\mathrm{O} 1 \mathrm{~s}$ for pristine and spent adsorbents were used to elucidate the $\mathrm{F}$ adsorption mechanism. The $\mathrm{O} 1 \mathrm{~s}$ spectra were simulated by considering $\mathrm{Al}-\mathrm{O}^{2-}, \mathrm{Al}-\mathrm{OH}, \mathrm{La}^{-} \mathrm{O}^{2-}$, and $\mathrm{La}-$ $\mathrm{OH}^{24,33}$ The XPS peaks of $\mathrm{Al}-\mathrm{O}^{2-}$ at $530.9 \mathrm{eV}$ and $\mathrm{Al}-\mathrm{OH}$ at $532.5 \mathrm{eV}$ were observed in AA (Fig. 7a). Similarly, the peak positions of $\mathrm{La}^{-} \mathrm{O}^{2-}$ at $530.7 \mathrm{eV}$ and $\mathrm{La}-\mathrm{OH}$ at $532.1 \mathrm{eV}$ were resolved in $\mathrm{LaOOH}$ (Fig. 7c). These four peaks were all detected
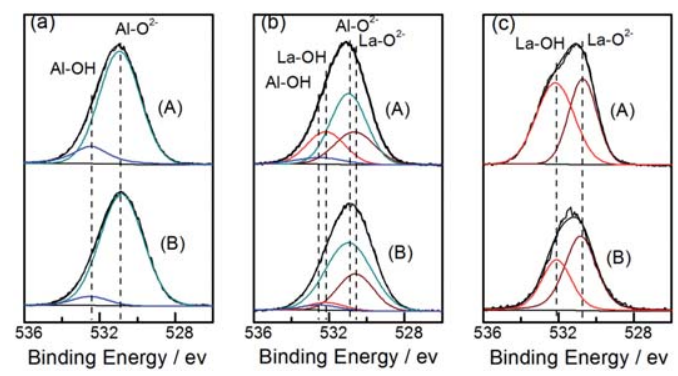

Fig. 7 High resolution XPS surveys of $O$ 1s for pristine (A) and spent (B) AA (a), LAA (b), and $\mathrm{LaOOH}$ (c). Vertical lines indicate binding energies of $\mathrm{Al}-\mathrm{O}^{2-}$ (cyan) at $530.9 \pm 0.1 \mathrm{eV}, \mathrm{Al}-\mathrm{OH}$ (blue) at $532.5 \pm 0.1 \mathrm{eV}, \mathrm{La}-\mathrm{O}^{2}$ (wine) at $530.7 \pm 0.1 \mathrm{eV}$, and $\mathrm{La}-\mathrm{OH}(\mathrm{red})$ at $532.1 \pm 0.1 \mathrm{eV}$. 
in LAA (Fig. 7b). The lower binding energies of $\mathrm{La}^{-} \mathrm{O}^{2-}$ and $\mathrm{La}-$ $\mathrm{OH}$, compared with those of $\mathrm{Al}-\mathrm{O}^{2-}$ and $\mathrm{Al}-\mathrm{OH}$, were in agreement with previous publications. ${ }^{\mathbf{2 4 , 3 3}}$ The difference in binding energies of $\mathrm{La}$ and $\mathrm{Al}$ can be attributed to the higher $\mathrm{CN}$ of $\mathrm{O}$ atoms with $\mathrm{La}(7.6$, Table $\mathrm{S} 2 \dagger$ ) than that with $\mathrm{Al}$ (4-6 (ref. $34)$ ), and the longer interatomic distance of La-O (0.25 nm, Table S2 $\dagger)$ than that of Al-O $(0.17-0.19 \mathrm{~nm}) .^{34}$

Similar results were observed in the high resolution XPS surveys of $\mathrm{F} 1 \mathrm{~s}$ for spent adsorbents (Fig. S6 $†$ ). The peaks of $\mathrm{F} 1 \mathrm{~s}$ were resolved into 685.7 and $684.4 \mathrm{eV}$ for $\mathrm{Al}-\mathrm{F}$ and $\mathrm{La}-\mathrm{F},{ }^{35,36}$ respectively. Al-F was obtained in AA and LAA, whereas La-F was obtained in LAA and LaOOH. The observed Al-F in LAA may be due to the exposure of alumina in LAA when polishing the sample for XPS analysis.

Upon $\mathrm{F}$ adsorption, the XPS peak intensities of $\mathrm{Al}-\mathrm{OH}$ on AA and La-OH on LAA and LaOOH decreased substantially (Fig. 7), indicating the reduction in hydroxyl group concentrations. However, the peak intensity of $\mathrm{Al}-\mathrm{OH}$ on LAA decreased only slightly, suggesting that $\mathrm{La}-\mathrm{OH}$ played a dominant role in $\mathrm{F}$ adsorption compared to $\mathrm{Al}-\mathrm{OH}$.

Raman analysis was used to study the interactions between La-OH and F (Fig. 8). The peak at $1162 \mathrm{~cm}^{-1}$ was observed in the spectra of spent LAA and $\mathrm{LaOOH}$ but not in that of AA, suggesting the formation of La-F bonds. The loss of $\mathrm{La}-\mathrm{OH}$ content (Fig. 7) and the occurrence of La-F bonds (Fig. 8) indicated the ligand exchange between $\mathrm{F}$ and hydroxyl groups on La-OH. Although the ligand exchange mechanism has been proposed by previous researchers,${ }^{37}$ our results provided direct experimental evidence and showed how the process occurred.

2To investigate the performance of LAA for $\mathrm{F}$ removal, isotherms were measured to determine the maximum $F$ adsorption capacity of AA and LAA (Fig. 9a). Adsorption isotherms of $\mathrm{F}$ followed the Langmuir equation: $C_{\mathrm{e}} / q_{\mathrm{e}}=1 / q_{\mathrm{m}} b+$ $C_{\mathrm{e}} / q_{\mathrm{e}}$, where $C_{\mathrm{e}}\left(\mathrm{mg} \mathrm{L}^{-1}\right)$ is the equilibrium concentration of $\mathrm{F}$, and $q_{\mathrm{e}}\left(\mathrm{mg} \mathrm{g}^{-1}\right.$, adsorbent) is the amount of F adsorbed; $q_{\mathrm{m}}(\mathrm{mg}$ $\left.\mathrm{g}^{-1}\right)$ and $b\left(\mathrm{~L} \mathrm{mg}^{-1}\right)$ are fitting parameters representing the maximum adsorption capacity and the adsorption affinity constant, respectively. The F adsorption on LAA $\left(16.9 \mathrm{mg} \mathrm{g}^{-1}\right)$ was 5.6 times higher than that of AA (Fig. 9a). Accordingly, the estimated density of functional surface sites on LAA (2.8 sites

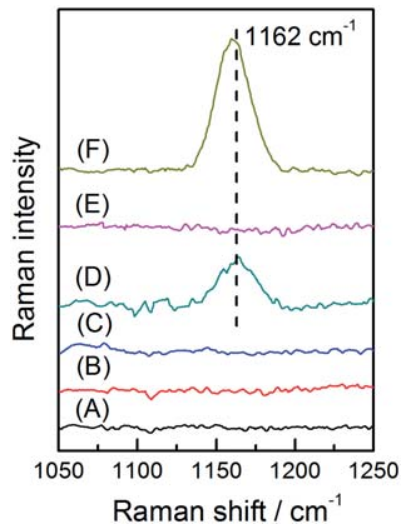

Fig. 8 Raman spectra of $A A(A), A A-F(B), L A A(C), L A A-F(D), L a O O H(E)$, and $\mathrm{LaOOH}-\mathrm{F}(\mathrm{F})$.
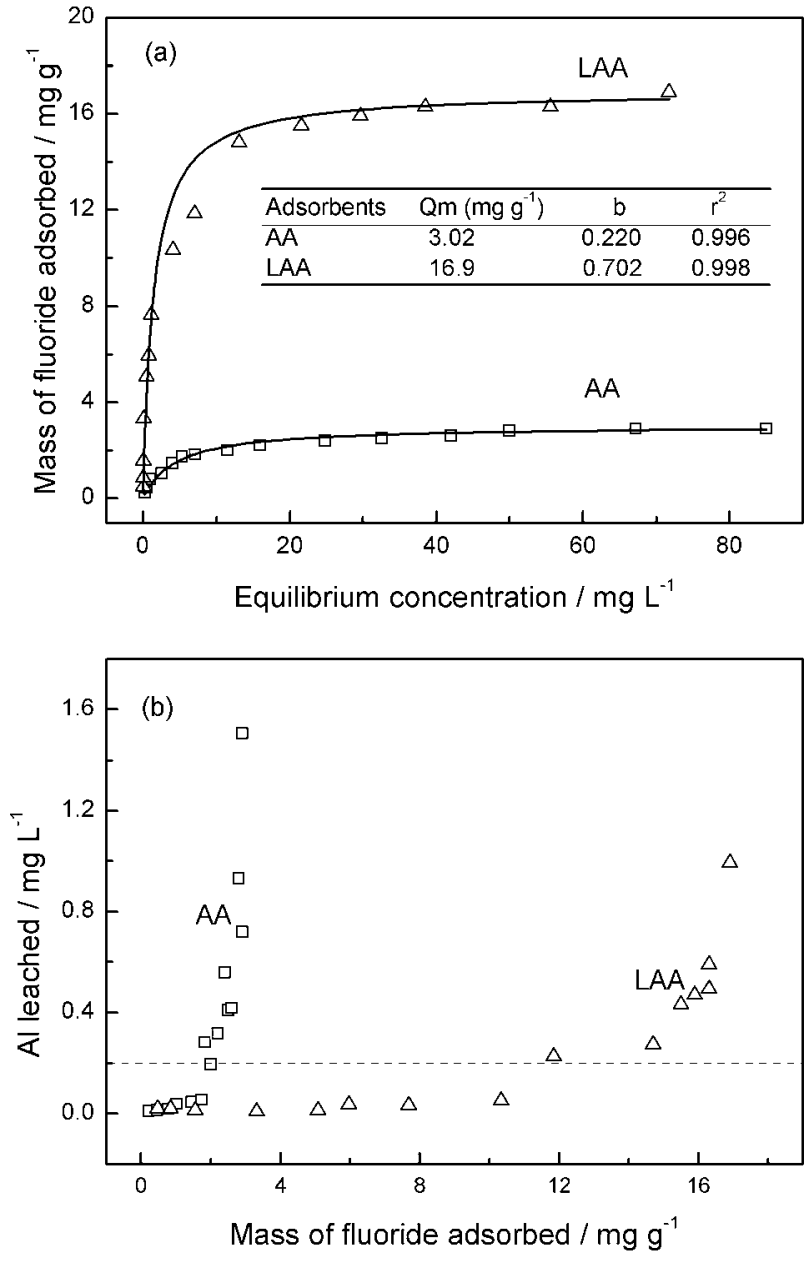

Fig. 9 Isotherm (a) and Al release (b) using AA and LAA for $F$ removal. Dashed line is the drinking water standard for $\mathrm{Al}\left(0.2 \mathrm{mg} \mathrm{L}^{-1}\right)$. Adsorbent $=1 \mathrm{~g} \mathrm{~L}^{-1}$, $\mathrm{pH}=7$, temperature $=298 \pm 2 \mathrm{~K}$. Inset table in (a) Langmuir parameters: $Q_{\mathrm{m}}$ is the maximum adsorption amount $\left(\mathrm{mg} \mathrm{g}^{-1}\right), b$ is Langmuir constant $\left(\mathrm{L} \mathrm{mol}^{-1}\right)$, and $r^{2}$ is the correlation coefficient.

$\left.\mathrm{nm}^{-2}\right)$ was 6.9 times more than that on AA $\left(0.4\right.$ sites $\left.\mathrm{nm}^{-2}\right)$. Our work improved considerably on the $\mathrm{F}$ adsorption capacity of La(III)-AA reported by Wasay $\left(6.23 \mathrm{mg} \mathrm{g}^{-1}\right) .{ }^{16}$

The Al release is a major consideration in $\mathrm{F}$ removal using AA. When $\mathrm{F}$ adsorption on AA was higher than $2 \mathrm{mg} \mathrm{g}^{-1}$ (Fig. 9b), the dissolved $\mathrm{Al}$ concentration exceeded $0.2 \mathrm{mg} \mathrm{L}^{-1}$, the WHO drinking water standard. The elevation of Al leaching with increasing $\mathrm{F}$ content can be ascribed to the F-promoted dissolution of $\mathrm{Al}_{2} \mathrm{O}_{3} \cdot{ }^{38}$ Conversely, the La impregnation suppressed the release of $\mathrm{Al}$ from LAA. The $\mathrm{Al}$ concentration in water treated with LAA was under $0.2 \mathrm{mg} \mathrm{L}^{-1}$ until the mass of $\mathrm{F}$ adsorbed reached $12 \mathrm{mg} \mathrm{g}^{-1}$. Meanwhile, the La concentration was in the range 8 to $146 \mu \mathrm{g} \mathrm{L}^{-1}$, which was an order of magnitude lower than the lowest commonly accepted concentration having adverse health effects. ${ }^{39}$

Another main limitation in using AA to remove $\mathrm{F}$ is its narrow $\mathrm{pH}$ range $(<6) .{ }^{6}$ However, the $\mathrm{pH}$ of natural groundwater with high 


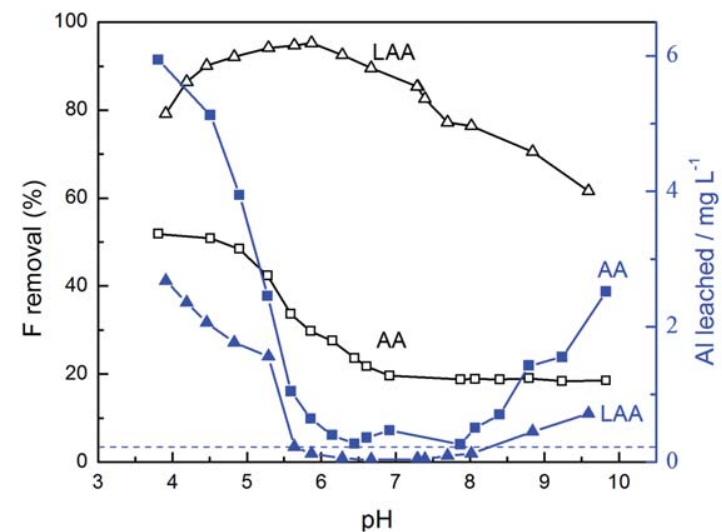

Fig. 10 F removal (open) and Al concentration (filled) of AA (squares) and LAA (triangles) as a function of $\mathrm{pH}$. Dashed line represents the $\mathrm{Al}$ drinking water standard. Adsorbent $=1 \mathrm{~g} \mathrm{~L}^{-1}$, initial $\mathrm{F}$ concentration $=10 \mathrm{mg} \mathrm{L}^{-1}$, temperature $=298 \pm 2 \mathrm{~K}$.

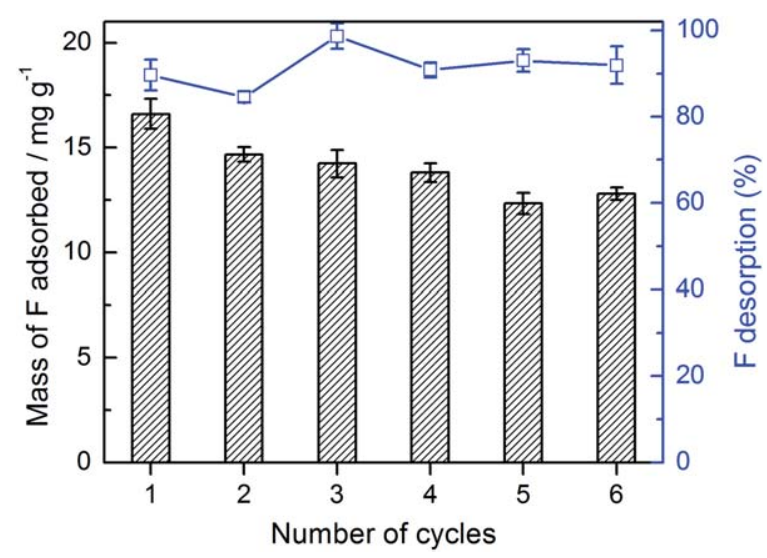

Fig. 11 Regeneration of LAA and F desorption.

fluoride is usually in the range of 7.6-8.6.1,40,41 Within this $\mathrm{pH}$ range, $\mathrm{F}$ removal using LAA reached 70.5-77.2\%, four times higher than that achieved using AA (Fig. 10). Meanwhile, Al leached from LAA was lower than $0.2 \mathrm{mg} \mathrm{L}^{-1}$ within the $\mathrm{pH}$ range 5.5-8. In contrast, the amount of $\mathrm{Al}$ released from AA cannot meet the WHO standard. Furthermore, the Al concentration increased significantly at $\mathrm{pH}<6$ and $\mathrm{pH}>8$ because of the amphoteric characteristics of $\mathrm{Al}$. In addition, the decreasing $\mathrm{F}$ removal at $\mathrm{pH}<$ 6 using LAA may be ascribed to La dissolution (Fig. S9†).

Regeneration is a critical factor of an adsorbent. The results in Fig. 11 show that the $\mathrm{F}$ desorption in the regeneration process was in the range $84-98 \%$. After 5 adsorption-regeneration cycles, the $\mathrm{F}$ adsorption capacity of LAA remained as high as $11.8 \mathrm{mg} \mathrm{g}^{-1}$ which is about four times higher than that of AA $\left(3.02 \mathrm{mg} \mathrm{g}^{-1}\right)$.

\section{Conclusions}

In summary, we have successfully synthesized and characterized LAA for effective $\mathrm{F}$ removal and investigated its ligand exchange mechanism. Five cycles of La impregnation on AA and calcination at $573 \mathrm{~K}$ improved the La content to $19.1 \%$, and achieved the maximum $\mathrm{F}$ adsorption at $16.9 \mathrm{mg} \mathrm{g}^{-1}$. The thin flake $\mathrm{LaOOH}$ on LAA was in an amorphous form with approximately 7.6 oxygen atoms around each La. LAA could adsorb $70.5-77.2 \% \mathrm{~F}$ in the $\mathrm{pH}$ range of the actual groundwater, about four times higher than $\mathrm{AA}$. Meanwhile, the $\mathrm{Al}$ release can be substantially reduced due to $\mathrm{LaOOH}$ formation. In addition, LAA can be regenerated and reused. XPS, Raman, and FTIR results show that ligand exchange between $F$ and surface hydroxyl groups is the mechanism for F adsorption on LAA. Our work presents an alternative solution for elevated $\mathrm{F}$ water treatment.

\section{Acknowledgements}

We acknowledge the financial support of the National Basic Research Program of China (2010CB933502) and the National Natural Science Foundation of China (20977098, 41023005).

\section{Notes and references}

1 S. Ayoob, A. K. Gupta and V. T. Bhat, Crit. Rev. Environ. Sci. Technol., 2008, 38, 401-470.

2 S. Hillier, C. Cooper, S. Kellingray, G. Russell, H. Hughes and D. Coggon, Lancet, 2000, 355, 265-269.

3 M. Agarwal, K. Rai, R. Shrivastav and S. Dass, J. Clean. Prod., 2003, 11, 439-444.

4 Y. Ku, H. M. Chiou and W. Wang, Sep. Sci. Technol., 2002, 37, 89-103.

5 V. S. Chauhan, P. K. Dwivedi and L. Iyengar, J. Hazard. Mater., 2007, 139, 103-107.

6 S. Jagtap, M. K. Yenkie, N. Labhsetwar and S. Rayalus, Chem. Rev., 2012, 112, 2454-2466.

7 B. D. Turner, P. Binning and S. L. S. Stipp, Environ. Sci. Technol., 2005, 39, 9561-9568.

8 S. S. Tripathy, J. L. Bersillon and K. Gopal, Sep. Purif. Technol., 2006, 50, 310-317.

9 S. S. Tripathy and A. M. Raichur, J. Hazard. Mater., 2008, 153, 1043-1051.

10 S. M. Maliyekkal, A. K. Sharma and L. Philip, Water Res., 2006, 40, 3497-3506.

11 S. X. Teng, S. G. Wang, W. X. Gong, X. W. Liu and B. Y. Gao, J. Hazard. Mater., 2009, 168, 1004-1011.

12 S. M. Maliyekkal, S. Shukla, L. Philip and I. M. Nambi, Chem. Eng. J., 2008, 140, 183-192.

13 K. Biswas, S. K. Saha and U. C. Ghosh, Ind. Eng. Chem. Res., 2007, 46, 5346-5356.

14 M. G. Sujana, G. Soma, N. Vasumathi and S. Anand, J. Fluorine Chem., 2009, 130, 749-754.

15 J. B. Zhou, Y. Cheng, J. G. Yu and G. Liu, J. Mater. Chem., 2011, 21, 19353-19361.

16 S. A. Wasay, S. Tokunaga and S. W. Park, Sep. Sci. Technol., 1996, 31, 1501-1514.

17 S. A. Wasay, J. Haron and S. Tokunaga, Water Environ. Res., 1996, 68, 295-300.

18 F. Luo and K. Inoue, Solvent Extr. Ion Exch., 2004, 22, 305322. 
19 Y. M. Zhou, C. X. Yu and Y. Shan, Sep. Purif. Technol., 2004, 36, 89-94.

20 A. Bansiwal, D. Thakre, N. Labhshetwar, S. Meshram and S. Rayalu, Colloids Surf., B, 2009, 74, 216-224.

21 N. Viswanathan and S. Meenakshi, J. Colloid Interface Sci., 2008, 322, 375-383.

22 B. K. Puri and S. Balani, J. Environ. Sci. Health, Part A: Toxic/ Hazard. Subst. Environ. Eng., 2000, 35, 109-121.

23 M. Bettman, R. E. Chase, K. Otto and W. H. Weber, J. Catal., 1989, 117, 447-454.

24 L. P. Haack, J. E. Devries, K. Otto and M. S. Chattha, Appl. Catal., A, 1992, 82, 199-214.

25 M. P. Rosynek and D. T. Magnuson, J. Catal., 1977, 46, 402413.

26 S. L. Zhong, B. Deng, A. W. Xu and S. P. Wang, Curr. Nanosci., 2011, 7, 407-414.

27 C. Y. Jing, J. L. Cui, Y. Y. Huang and A. G. Li, ACS Appl. Mater. Interfaces, 2012, 4, 714-720.

28 J. Yang, L. Zhou, L. Z. Zhao, H. W. Zhang, J. N. Yin, G. F. Wei, K. Qian, Y. H. Wang and C. Z. Yu, J. Mater. Chem., 2011, 21, 2489-2494.

29 L. M. Camacho, A. Torres, D. Saha and S. G. Deng, J. Colloid Interface Sci., 2010, 349, 307-313.

30 M. Jang, J. K. Park and E. W. Shin, Microporous Mesoporous Mater., 2004, 75, 159-168.
31 P. Malet, M. J. Capitan, M. A. Centeno, J. A. Odriozola and I. Carrizosa, J. Chem. Soc., Faraday Trans., 1994, 90, 27832790.

32 F. Ali, A. V. Chadwick and M. E. Smith, J. Mater. Chem., 1997, 7, 285-291.

33 L. Katta, T. V. Kumar, D. N. Durgasri and B. M. Reddy, Catal. Today, 2012, 198, 133-139.

34 G. Gutierrez and B. Johansson, Phys. Rev. B: Condens. Matter, 2002, 65, 104202.

35 S. D. Yao, Y. Zheng, L. H. Ding, S. Ng and H. Yang, Catal. Sci. Technol., 2012, 2, 1925-1932.

36 L. Armelao, G. Bottaro, G. Bruno, M. Losurdo, M. Pascolini, E. Soini and E. Tondello, J. Phys. Chem. C, 2008, 112, 1450814512.

37 B. Kasprzyk-Hordern, Adv. Colloid Interface Sci., 2004, 110, 19-48.

38 W. Stumm, Chemistry of the solid-water interface: processes at the mineral-water and particle-water interface in natural systems, John Wiley \& Sons Inc., USA, 1992. pp. 165-169.

39 S. Hirano and K. T. Suzuki, Environ. Health Perspect., 1996, 104, 85-95.

$40 \mathrm{~S} . \mathrm{Hu}, \mathrm{T}$. Luo and C. Jing, J. Geochem. Explor., 2012, DOI: 10.1016/j.gexplo.2012.08.013.

41 V. K. Saxena and S. Ahmed, Environ. Geol., 2001, 40, 10841087. 